\title{
Ecological Perspectives on Religion and Positive Youth Development
}

\author{
Mona M. Abo-Zena ${ }^{1, *}$ and Meenal Rana ${ }^{2}$ \\ 1 Department of Curriculum \& Instruction, University of Massachusetts Boston, Boston, MA 02125, USA \\ 2 Department of Child Development and Family Relationships, Humboldt State University, \\ Arcata, CA 95521, USA; Meenal.Rana@humboldt.edu \\ * Correspondence: mona.abozena@umb.edu
}

Received: 30 May 2020; Accepted: 30 July 2020; Published: 7 August 2020

\begin{abstract}
A positivist orientation that marginalized the study of religion and spirituality in social science research has limited both its scope and focus. Given a primarily cognitive orientation to this inquiry, children, adolescents, and emerging adults were typically not the focus of research. More recently, the scope of research has been broadened to emphasize the need to understand contextual and developmental nuances, which are increasingly being reflected in a range of research designs, methods, and samples. The burgeoning scholarship on the role of religion and spirituality in the development of youth during this particularly formative developmental period has begun to shed light on how religion promotes and challenges positive youth development. While this expanding focus has begun to describe youth's developmental experiences, the deep interconnections between individual youth, religious and spiritual systems, and the contexts and relationships in which youth develop remain understudied. This special issue on the role of religion and spirituality on positive youth development asserts the import of exploring ecological perspectives and influences when studying the role of religion and spirituality in the development of diverse youth and draws from interdisciplinary and lifespan perspectives to continue mapping the terrain of this area of study and ways to navigate it.
\end{abstract}

Keywords: religion; spirituality; positive youth development; intersectionality; mixed-methods; lifespan; context; ecological framework

\section{Ecological Perspectives on Religion and Positive Youth Development}

Although religion and spirituality have been central to the human experience, their study within human development and psychology has been marginalized given the dominance of a positivist orientation, a school of thought that argues that knowledge generation is based on empirically verified data. As the study of religion and spirituality regained attention within psychology, it has been critiqued that its representation has favored Mainline Protestant, European American, Christian samples (Hill and Pargament 2003). From a lifespan perspective that includes from conception through old age, Oser et al. (2006) reviewed the theoretical and empirical scholarship describing religious and spiritual development. From a relational developmental systems (RDS) perspective, which allows examination of the influence of supernatural beliefs on development, religious development can be understood as an individual's abilities to participate in rituals and practices of a religion and their engagement with religious communities and traditions over time. Spiritual development is an individual's experience and their response to transcendence (King and Boyatzis 2015). Embedded in an ecological perspective, this special issue focuses on positive youth development from a lifespan perspective and centers on children's and adolescents' development in the contexts of parenting, schools, religious and ethnic 
communities, and organizations. The macro level contexts of religious ideologies shape the supports and constraints for families and their children (Burr et al. 2011).

In some studies, religion was found to contribute both to adolescents' personal meaning and prosocial concerns for others; religion was associated with positive youth development (Furrow et al. 2004; Richert and Granqvist 2013). Although recent decades have marked a burgeoning focus on the role of religion and spirituality in the positive development of youth, these studies have mostly yielded a host of bivariate associations between religion and spirituality and a range of youth outcomes, with inadequate attention to particular developmental processes (Hardy and King 2019; Marks and Dollahite 2011). Further, King and Boyatzis (2015) warned that, "[t]the measures and methods typically used by developmentalists may simply be inadequate for the task of assessing young children's spirituality" and particularly that their communication abilities may be inadequate to describe experiences such as transcendent connectedness (p. 1012). In addition to limitations in the methods and representative sampling of diverse youth, the scholarship in religion and spirituality in the lives of youth has lacked attention to the varied levels of contexts and culture that inform youth experiences (Abo-Zena and Ahmed 2014). A contextualized exploration of youth's religious and spiritual experiences should encompass ecological influences in a person-centered and intersectional manner that addresses youth's privileged and marginalized positions and meaning making around them (Abo-Zena and Rana 2015; Spencer 2017).

Given that there remain multiple underexplored processes and contexts that shape how religion informs the positive development and outcomes for diverse youth and families, we encourage designing scholarship to fill these gaps. In particular, such issues can be addressed by drawing from more inclusive and representative samples (e.g., study participants from different backgrounds), by acknowledging religious content, and by embedding studies in the range of ecological contexts and the interactions between the individuals and the context in a relational systems manner (Lerner et al. 2015).

\section{Inclusive and Representative Samples}

As in the study of any complex issue, research samples should represent the entirety of the phenomena both in terms of depth as well as breadth of the role of religion and spirituality in positive youth development. Sampling techniques should help elicit experiences that are both idiographic (unique to a particular faith tradition or particular child) and nomothetic (pancultural) (Bloom 2007; Schachter and Hur 2019) and capture experiences throughout the lifespan, particularly from early childhood to emerging adulthood, due to the formative nature of this time. These years provide foundational experiences and include acquiring beliefs, engaging in relevant practices, and exploring identity, with continued development throughout adulthood. In order to have more inclusive and representative samples, the research field (and individual studies according to the scope of a particular project), should consider how to include a taxonomy of sources of variations that include: personal-social identifiers (e.g., race, ethnicity, gender, sexuality, ability, socioeconomic status, nation of origin and their intersections); geographic representation (i.e., to account for regional variations and similarities, socio-historical fluctuations including reflections of human transnationalism and migration, and geo-cultural influences reflecting international sampling); religious affiliation (e.g., Abrahamic and non-Abrahamic traditions, theistic, polytheistic, pagan, atheist, agnostic); and religious/spiritual commitments (e.g., level of religious/spiritual belief, engagement in practices, salience of religious identity). These variations should account for fluidity of these factors and their interactive nature in context and throughout an individual's lifespan trajectory. It is important to continue exploring the role of religion and spirituality with groups relatively well-represented in the literature, recognizing that there is still much we do not know about their developmental processes. Additionally, scholars should explore underrepresented groups, particularly groups who are religiously minoritized (e.g., Sikh, Muslim, Jewish, Jain, Ba'hai, Buddhist, Hindu) and variations in perspectives, commitments, and experiences within populations as related to personal-social identifiers (e.g., South Asian Christian, Black Jewish). 


\section{Religious Content and Its Developmental Implications}

Embedded in exploring issues related to religious and spiritual affiliation and denomination, the study of the role of religion in positive youth development requires researchers to have religious literacy that enables them to recognize and understand the basic tenets of other faith traditions. With increasing waves of migration bringing increased religious diversity to our interactions, would researchers recognize a youth referencing a Buddhist shrine at home, religious dress or marker, or mentioning a phrase or belief of religious import (Levitt 2007)? Researchers and practitioners, however, should take caution in exercising their knowledge and understanding of a religion or religious practices, especially if they are not from the religious group of study, to avoid making assumptions. However, over competence might lead to not asking important questions of youth and their spiritual experiences. Meaningful work in the field warrants open mindedness and a lifelong learning approach.

Distinct from religious education or ideological teaching, religious literacy takes a cultural approach that assumes religious traditions to be internally diverse and situated in cultural context (Moore 2016). This cultural approach provides a general map of religious and spiritual life and the particular terrain of important constructs, practices, values, and meanings that a researcher should consider. For example, exploring religious practices may include investigating not just dietary rules and restrictions (e.g., vegetarianism, halal, kosher, consumption/prohibition of particular foods at particular times), but also the reasons for the dietary rules that bind faith adherents as well as other souls or ancestral spirits. How children learn about the rules and are socialized to follow (or not follow them) may affect youth development. Other faith traditions may feature particular healing and healers, as well as agents of spiritual import (e.g., holy water, cedar branches, sage) and various religious rituals (e.g., fire ceremonies, dances and communal singing, chanting). "Ritual is fundamentally a prescribed pattern of behavior, hence behavior that is structured, otherwise it will not be considered effective for whatever purpose is intended. Some rituals, particularly public and religious ones, are often rigidly patterned" (Spilka 2005, p. 365). Religious rituals play a role in reinforcing beliefs, providing experiences, and building a sense of community (Spilka 2005), a useful entry point to studying religious socialization and developmental processes related to engaging with rituals. Rituals also engage children and youth through participation and asking questions about the practices (Harris and Koenig 2006). Sometimes, people who may not be religious also participate in the religious rituals, and hence are included in the community. Some people participate in religious ceremonies or rituals to become part of a religious and cultural community to avoid marginalization in a newer context. For example, many immigrant groups might have a higher need for ethnic and cultural communities in preserving their religious, cultural, and ethnic values (Feguson et al. 2016). Religious and ethnic identities often are reconstructed more intentionally after immigration to new contexts. Immigrants might attend religious services more frequently than they would do in their home country, not because they want to socially isolate themselves, but because they want to stay close to it in order to socialize their children and to preserve the values, and also to be in a stronger position to interact with other social or religious groups (Williams 2007).

\section{Bioecological Contextual Developmental Iterations}

Religious content is embedded in the lived experiences of youth who navigate their ecological contexts (Bronfenbrenner and Morris 2006). A contextual approach includes relational developmental systems (RDS), as it provides a comprehensive framework that highlights the bi-directional relationships between different levels of the developing systems (Lerner et al. 2015). These developmental contexts include the individual embedded in different socializing relationships, primarily parents (Berns 2015) but also including relationships with peers (Brown 2004) and religious and spiritual mentors (Schwartz et al. 2006). Youth also develop within particular contexts, such as proximal spaces of home, youth group, congregation, as well as more distal influences such as broader society and public policy and perceptions that afford privileges or slights based on multiple axes of identity (Abo-Zena and Ahmed 2014). Religion and spirituality provide youth with different sources of hope, 
ideals, moral beliefs, behavioral norms, and worldviews through texts, prayers, and rituals and role models through the collective nature of religion and influence the course of identity development during adolescence (Roeser et al. 2008; Smith and Denton 2005). The communities where adolescents grow are structured within cultural, historical and religious traditions, which help youth to develop a sense of social belonging, find meaning and purpose in their life, and boost self-esteem and understanding, hence helping shape youth's identities (Ashmore et al. 2004; Ho and Ho 2007).

Children's and youth's individual characteristics, such as personalities, temperament, individual desire to search and explore religiosity and spirituality, cognitive and moral development, and disabilities play an important role in their religious and spiritual development. Harris and Koenig (2006) argued that in addition to maturation processes in cognitive development, the exposure to rituals, religious buildings, art and drawing, and ceremonies promote the understanding of higher power as children start developing intuitive thought and asking questions by age 3-4, leading to a range of ways children are socialized religiously, evaluate scientific and religious evidence, and develop perspectives about God, spirit, life, and faith. Youth develop their persona within the norms of their social and cultural environment; hence religion is an important construct in youth's identity (Erickson 1968). Families and communities are structured within cultural, historical, and religious traditions, which helps youth to have a sense of social belonging, find meaning and purpose in their life, boost self-esteem and understanding, and contribute to shaping youth's identities (Ashmore et al. 2004; Ho and Ho 2007). There are particular interactions between the individual and context that affect religious experiences, which inform developmental trajectories.

To illustrate, in addition to being able to understand and recognize the traditions of others, religious literacy includes understanding and accessing one's faith tradition. In some traditions, accessing religion requires proficiency in a liturgical language, which may limit access. Oftentimes the religious content is accessible to few elites and interpreted and transmitted to other members of the cultural group at the mercy of the elites. One such example is the traditional religious content of Hinduism that is written in Sanskrit. According to Vajpeyi (2016), "Sanskrit is an old language rich with liturgy, scripture, philosophy, and literature, but its use has, for the most part, been restricted to men and religious and political elites" (p. 46). Some of these elites included "Brahmins", a caste that was deemed on the top of the caste hierarchy, who did not allow "Shudras", who were deemed lowest on the caste ladder, to learn the language. Additionally, the interpretation of the religious content to lay people also relied upon Brahmins, which affected the understanding and practice of religion across Hindus from various ethnic and caste groups. The accessibility and interpretation of religious content might shape the understanding and practice of religion. This social stratification of religious, cultural, and spiritual contexts shapes the socialization of children and youth in the families embedded in the societal hierarchy of privilege and oppression.

\section{Reflexivity}

Reflexivity is important in critical inquiry and conceptualization of this issue. Reflexivity should be understood beyond self-critique and appraisal; it is the continuous engagement of various selves in the process and product of the inquiry (Dowling 2006; Horsburgh 2003). Reflexivity also constitutes our internal and external awareness as researchers/editors, while being aware of the effects of our cultural, religious, and professional backgrounds, and our professional relationships to other contributors of the issue in understanding and interpreting the works of this journal (Dowling 2006).

Mona Abo-Zena, PhD: As an immigrant origin child, I grew up in small town Iowa, U.S. where the only other Muslim people in my town lived with me (my mother, father, and brother). Being religiously minoritized in a geographically isolated religious context limited my own knowledge of Islam (e.g., fortunate to have been taught to speak colloquial Arabic, but not proficient in understanding and decoding liturgical and classical Arabic), and left me struggling to reconcile being socially-religiously different. My childhood memories are characterized largely by the mental fog of navigating this duality. Particularly salient during the massive stretch between Thanksgiving, Christmas, and New Year's, 
I recall mouthing the words to Christmas carols in public school (and in middle school learning them in Spanish as well). As an educator and developmental scholar, I am committed to striving to study people and their experiences in a holistic, intersectional, and nuanced manner as they would like to be described. I am particularly attentive to individuals and groups who are often rendered invisible or marginalized in scholarship, including youth who are religiously minoritized and young children. Guided by insights from my own personal experiences of invisibility or marginalization, my scholarly focus, including for this special issue, seeks to make up for such ecological omissions and center around the people and experiences typically underrepresented within the scholarship.

Meenal Rana, PhD: At Humboldt State University, I teach many classes in Child Development using lifespan and ecological perspectives. Students in my classes learn about growth and development from conception to adulthood using various frameworks: (1) Bronfenbrenner's bioecological model (i.e., various layers of context shaping development; individual characteristics affect contexts); risk and resilience framework (i.e., using strength based perspectives); sociocultural lens (i.e., role of familial and cultural contexts); neurosequential model of education (i.e., safety and relationships with young children are foundations of learning); family systems perspectives, genetics, and epigenetics. I integrate these lenses in my research and community work by incorporating interdisciplinary knowledge from the areas of psychology, neuroscience, human genetics, social work, education, and sociology. I am an immigrant woman scholar, who grew up in India in a Hindu family. While using an egalitarian lens of viewing other religious groups, there was a lot of emphasis on prayers and rituals. As a critical thinker myself, I often found myself asking lots of "why" and "how" questions about the religion. I integrated the ideologies for which I could find more plausible rationale from my parents. As an adult, I do not consider myself religious but highly spiritual. However, as a first-generation immigrant and a religious scholar who worked with Sikh families, I am also cognizant of the intersectionality of culture and religion and the importance of religious congregations and community in fostering cultural values in next generation, in building social and economic capital and resilience in the face of discrimination and marginalization. Being aware of my own characteristics and biases, I was able to engage in this review process objectively, while keeping an openness for participants' voices and experiences, researchers' interpretations of their data, and authors' writing styles.

\section{This Issue}

Drawing from an ecological framework and life span perspective, this special issue on the role of religion and spirituality in positive youth development addresses some gaps in scholarship. Using interdisciplinary conceptual frameworks and diverse research methods, it focuses on studying underrepresented populations, developmental outcomes of religiosity and spirituality, contexts of socialization, and perspectives within positive youth development as well as challenges to it. While the focus is on the role of religion and spirituality, the framing is from an intersectional perspective on religious identity development that attends to other social positions and identities in contexts that are differentially stratified such as ethnicity, race, gender, socioeconomic background, nationality, and immigration status (Crenshaw 1989) Collectively, the papers draw from diverse approaches to contribute to the conceptual framings and empirical evidence to understand the role of religion and spirituality in the positive development of youth.

This special issue contributes to the existing literature in multiple ways: 1 . While youth development generally focuses on adolescence and emerging adulthood, this special issue draws from a lifespan perspective in order to consider antecedents in early childhood and the effects of socializing agents throughout the lifespan, including caregivers and religious mentors, as well as the effects of contexts such as racism and xenophobia on youth development; 2 . The field of the psychology of religion has been identified as being disproportionately focused on Protestant Christian samples, experiences, and theology; this issue seeks to represent underrepresented faith traditions and their related experiences; 3 . With a focus on supporting positive youth development, this issue draws from interdisciplinary perspectives (e.g., religious studies, disability studies, education, family 
studies, developmental psychology, critical race and ethnic studies, urban studies, sociology) and the correspondingly diverse research methods and conceptual models to understand the complex developmental processes and interplay between religion and other social identities in context.

\section{Issue Overview and Contributions}

The special issue consists of seven articles, five empirical studies, one conceptual, and one review paper. Using the bioecological framework and lifespan development perspective, these quantitative and qualitative studies collected data from young children, youth, families, religious organizations and congregations. The methodologies included autoethnography, ethnography, in-depth interviews, case studies, and structural equation modeling. The samples ranged from three case study vignettes to 888 youth. The youth represented in the articles report following religious traditions that include Judaism, Christianity (including Catholicism), Islam, and Sikhism, intersecting with many ethnic, racial, and immigrant, and international populations, such as Black, El Salvadorian, first- and second-generation Indian immigrant families. The studies examined the contexts of parents and families, religious schools, organizations, education and texts, congregations, religious and non-religious communities, contemporary and historical contexts, popular media and stereotyping, stratified social contexts given effects of racism, classism, and other interlocking systems of oppression prevalent in society. This issue highlighted understudied religious socialization contexts for children and adolescents whose traditions and experiences have not typically been the focus of research, noting that there are many competing socialization contexts and phenomena that affect the religious and spiritual development of children and youth.

King et al. (2020) explore the link between religiousness and hope, particularly for youth living in adversity. Drawing on a relational developmental systems metatheory, this study explored how involvement in the faith-based youth-development organization, Compassion International (CI), might facilitate character strengths like hope for a youth sample in El Salvador, half of whom were involved in CI and the other half of whom were a locally matched counterfactual sample. Structural equation models revealed that higher levels of religiousness were directly and indirectly associated with higher levels of hope in relation to higher levels of spirituality and social connections among $\mathrm{CI}$ involved youth. Findings suggest that the relationship between religiousness and hope is best understood when it incorporates the spirituality and social connections associated with religion of youths.

Expanding on how social science research has typically portrayed the lived experiences of Black urban-residing people in a manner that flattens our understanding of their experiences, Mattis et al. (2019) propose an alternative conceptual framework that links sociopolitical factors to religiosity, spirituality, and positive development. In particular, this lens portrays the diversity of religious and spiritual experiences and the robust connections between everyday life and positive outcomes, such as compassion, hope, liberation, and joy and attends to the ways that faith helps Black youth and adults residing in urban spaces navigate the sequelae of distinct sociopolitical features of urban life.

Drawing from a sociocultural lens, Abo-Zena and Midgette (2019) use illustrative examples of lived experiences to frame the robust nature of young children's participation in religious life and how they make meaning around and apply religion to their own lives. They attend particularly to religious minorities and contexts relevant to religious socialization and development. While the sociocultural perspective captures the range of children's experiences, the manuscript explores the understudied role of emotion as a motivator or influence of young children's experiences.

Using the ethnoreligious socialization framework, adapted from the ethnic racial socialization work done in African-American families, Rana et al. (2019) present ethnographic work with a Sikh community in a Midwestern town. Using the bioecological framework, the authors draw from 23 parent interviews and observation notes from 12 Sikh families on their socialization of their sons to protect them from bullying and harassment that happens in schools due to popularized media images 
maligning Muslims and Sikhs mistaken as Muslims. Additionally, the paper examines the role of ethnoreligious communities in building resilience among minoritized youth.

Crawford Sullivan and Aramini (2019) used qualitative semi-structured, face-to-face interviews with 53 parents/caregivers to analyze barriers and opportunities in religious education for their children and adolescents with autism spectrum disorder (ASD). The authors examine the factors parents of children with ASD perceive or experience within religious education as supportive or as barriers that exacerbate the alienation from the community. The authors present recommendations for congregations and religious places of worship to be more inclusive of children and families with exceptionalities.

Within the context of religious education classroom, Hassenfeld (2019) reports on a year-long intervention conducted in a seventh grade Hebrew Bible classroom in which students were asked to find their own meaning in the Biblical text and the role of the teacher in that iterative process. This autoethnographic study found that religious text classrooms can offer a particular ecological context to support positive youth development when an effective interpretive community is created.

Dollahite and Marks (2019) highlight contributions of the findings from a branch of the American Families of Faith national research project that pertain to positive religious and spiritual development in youth. In this empirical review of six previous studies on religious youth and their parents from diverse Abrahamic faith communities (various denominations in Christianity, three major branches of Judaism, and two major groups in Islam), they review findings in family contexts, and outline areas for future scholarship.

\section{Limitations and Future Directions}

In spite of the important contributions to this special issue, it is limited in its scope. While we focused on ecological perspectives on religion and positive youth development, we recognize that what constitutes positive development may vary based on religious affiliation and from an intersectional perspective (e.g., comportment and knowledge requirements that vary by religion and are often gendered, need to understand a liturgical language to participate in religious practices). Given the vast possibilities of factors and their relative fit between individual children or youth and their social contexts over time, not all could be included within the scope of an issue. Dollahite and Marks (2019) outline a list of areas for future research that includes: social and political action, popular media, participating in secular activities, wrestling with existential questions, conversion and disaffiliation, interfaith knowledge and experiences, impactful personal experiences, volunteerism and service, religious rituals and ceremonies, mental illness, mindfulness and meditation, temperament and personalities, agency and personal choices, sexual orientation and experiences, the dark side of religion, and generative devotion that tends to the needs of others, particularly family.

We concur with the direction they outline and contribute examples that stem from responsiveness to more inclusive sampling in order to anchor future research opportunities. We need to continue exploring the degree to which the content of religious affiliation includes variations within and across different populations of youth. This research focus would include cultural, religious, and secular practices, and focus on the meaning making youth ascribe to them at the time, over time, and across geographical contexts. For example, alms giving or tithing may be practices that exist in some form across faith traditions, but be engaged in for a range of reasons (e.g., purifying wealth and the giver, for protection from evil spirits, a way to save money and provide for someone else in need, a compulsory tax). Scholars should seek to understand the different meanings that children and youth afford to their practice and explore the implications for religious and spiritual development. A research focus that seeks inclusively to represent religious/spiritual commitments experiences may explore features of religious life for which there may be no common or adequate parlance for communicating the mysteries of experiences like fasting and transcendence. Finally, research methods and researchers need to be keen to uncover meaning making and utilize multimethod approaches, multicontextual studies, and multiple participants and perspectives to provide both divergent and triangulated data. Longitudinal studies, participant centered approaches, and autoethnography provide a range of research designs that can 
solve the problem of narrow ways of studying religion (i.e., considering attendance as a proxy of religiosity, when attendance may be about accessing co-ethnic fellowship or material support such as free food provided by a Sikh temple and not [only] for religiosity).

In order to actualize the potential of research to authentically understand the phenomena of religion and spirituality as it informs the development of diverse youth, we need to broaden the research lens to include the diverse youth, families, and congregations within fluid and multi-layered contexts. Such a focus will help identify practices that may be currently overlooked in the developmental scholarship, such as Holi or the Hindu Festival of Colors and its focus on forgiveness and inclusiveness, with implications for research methods and understanding developmental processes. A person-centered focus would explore the range of effects religion may have, including presenting barriers to normative youth development. For example, immigrant ethnoreligious groups might bring their religious and cultural practices to a new homeland and the enculturation process can be challenging due to lack of religious community in a particular geographic area. The competing contexts of immigrant religious minorities and the separation of state and religion can affect the family dynamics and pose challenges for youth mental health. More intersectional scholarship that includes a youth's personal and social identifiers and the integration of multidimensional aspects of identity into a coherent self within layers will help ensure that developmental scholarship serves to promote the positive development of a range of youth in context as they relate to others, and not be a disservice to all youth by neglecting all who are important.

Author Contributions: Conceptualization, M.M.A.-Z. and M.R.; writing-original draft preparation, M.M.A.-Z. and M.R.; writing-review and editing, M.M.A.-Z. and M.R. All authors have read and agreed to the published version of the manuscript.

Funding: This research received no external funding.

Conflicts of Interest: The authors declare no conflict of interest.

\section{References}

Abo-Zena, Mona M., and Sameera Ahmed. 2014. Religion and spirituality of emerging adults: Processing meaning through culture, context and social position. In Emerging Adults' Religiousness and Spirituality: Meaning-Making in an Age of Transition. Edited by C. M. Barry and M. M. Abo-Zena. New York: Oxford University Press, pp. 220-36.

Abo-Zena, Mona M., and Allegra Midgette. 2019. Developmental implications of children's early religious and spiritual experiences in context: A sociocultural perspective. Religions 10: 631. [CrossRef]

Abo-Zena, Mona M., and Meenal Rana. 2015. Immigrant religions and religious contexts. In Transitions: The Development of Immigrant Children. Edited by Carola Suárez-Orozco, Mona M. Abo-Zena and Amy Marks. New York: New York University Press, pp. 80-96.

Ashmore, Richard D., Kay Deaux, and Tracy McLaughlin-Volpe. 2004. An organizing framework for collective identity: Articulation and significance of multidimensionality. Psychological Bulletin 130: 80-114. [CrossRef] [PubMed]

Berns, Roberta M. 2015. Child, Family, School, Community: Socialization and Support. Stamford: Cengage Learning. Bloom, Paul. 2007. Religion is natural. Developmental Science 10: 147-51. [CrossRef] [PubMed]

Bronfenbrenner, Urie, and Pamela A. Morris. 2006. The bioecological model of human development. In Handbook of Child Psychology: Vol 1, Theoretical Models of Human Development, 6th ed. Edited by Richard M. Lerner and William Damon. Hoboken: Wiley, pp. 793-828.

Brown, B. Bradford. 2004. Adolescents' relationships with peers. In Handbook of Adolescent Psychology. Edited by Richard Lerner and Laurence Steinberg. New York: Wiley, vol. 2, pp. 363-94.

Burr, Wesley R., Loren D. Marks, and Randal D. Day. 2011. Sacred Matters: Religion and Spirituality in Families. New York: Routledge.

Crawford Sullivan, Susan, and Victoria Aramini. 2019. Religion and positive youth development: Challenges for children and youth with autism spectrum disorder. Religions 10: 540. [CrossRef] 
Crenshaw, Kimberle. 1989. Demarginalizing the intersection of race and sex: A black feminist critique of antidiscrimination doctrine, feminist theory and antiracist politics. University of Chicago Legal Forum 1: 139-67. Available online: https://chicagounbound.uchicago.edu/cgi/viewcontent.cgi?article=1052\&context=uclf (accessed on 15 January 2019).

Dollahite, David C., and Loren D. Marks. 2019. Positive youth religious and spiritual development: What we have learned from religious families. Religions 10: 548. [CrossRef]

Dowling, Maura. 2006. Approaches to reflexivity in qualitative research. Nursing Researcher 13: 7-21. [CrossRef]

Erickson, Erik. 1968. Identity: Youth and Crisis. New York: Norton.

Feguson, Gail M., Catherine L. Costigan, Christy V. Clarke, and Julianna S. Se. 2016. Introducing remote enculturation: Learning your heritage culture from afar. Child Development Perspectives 10: 166-71. [CrossRef]

Furrow, James L., Pamela E. King, and Krystal White. 2004. Religion and positive youth development: Identity, meaning, and prosocial concerns. Applied Developmental Science 8: 17-26. [CrossRef]

Hardy, Sam A., and Pamela E. King. 2019. Processes of religious and spiritual influence in adolescence: Introduction to a special section. Journal of Research on Adolescence 29: 244-53. [CrossRef]

Harris, Harris L., and Melissa A. Koenig. 2006. Trust in testimony: How children learn about science and religion. Child Development 77: 505-24. [CrossRef] [PubMed]

Hassenfeld, Ziva. 2019. Studying sacred texts as a pathway to positive youth development: Middle.school students read Hebrew Bible. Religions 10: 379. [CrossRef]

Hill, Peter C., and Kenneth Pargament. 2003. Advances in the conceptualization and measurement.of religion and spirituality. American Psychologist 58: 64-74. [CrossRef] [PubMed]

Ho, David Y. F., and Rainbow T. H. Ho. 2007. Measuring spirituality and spiritual emptiness: Toward and transcultural applicability. Review of General Psychology 11: 62-74. [CrossRef]

Horsburgh, Dorothy. 2003. Evaluation of qualitative research. Journal of Clinical Nursing 12: 307-12. [CrossRef] [PubMed]

King, Pamela E., and Chris Boyatzis. 2015. Religious and spiritual development in childhood and adolescence. In The Handbook of Child Psychology and Developmental Science: Social and Emotional Issues, 7th ed. Edited by Michael E. Lamb and C. G. Coll. Hoboken: Wiley, vol. 3, pp. 975-1021.

King, Pamela Ebstyne, Jennifer Medina Vaughn, Yeonsoo Yoo, Jonathan M. Tirrell, Elizabeth M. Dowling, Richard M. Lerner, G. John Geldhof, Jacqueline V. Lerner, Guillermo Iraheta, Kate Williams, and et al. 2020. Exploring religiousness and hope: Examining the roles of spirituality and social connections among Salvadoran youth. Religions 11: 75. [CrossRef]

Lerner, Richard M., Jacqueline V. Lerner, Edmond Bowers, and G. John Geldhof. 2015. Positive youth development: A relational developmental systems model. In Handbook of Child Psychology and Developmental Science: Vol. 1. Theory and Method, 7th ed. Edited by Willis Overton, Peter Molenaar and Richard M. Lerner. Hoboken: Wiley, pp. 607-51.

Levitt, Peggy. 2007. God needs no passport. In Immigrants and the Changing American Religious Landscape. New York: The New Press.

Marks, Loren D., and David C. Dollahite. 2011. Mining the meanings and pulling out the processes from psychology of religion's correlation mountain. Psychology of Religion and Spirituality 3: 181-93. [CrossRef]

Mattis, Jacqueline S., Gordon J. Palmer, and Meredith O. Hope. 2019. Where our bright star is cast: Religiosity, spirituality, and positive Black development in urban landscapes. Religions 10: 654. [CrossRef]

Moore, Diane L. 2016. Diminishing religious literacy: Methodological assumptions and analytical frameworks for promoting the public understanding of religion. In Religious Literacy in Policy and Practice. Edited by Adam Dinham and Matthew Francis. Bristol: University of Bristol Policy Press, pp. 27-38.

Oser, Fritz K., W. George Scarlett, and Anton Bucher. 2006. Religious and spiritual development.throughout the lifespan. In Handbook of Child Psychology, 6th ed. Edited by William Damon and Richard M. Lerner. Theoretical Models of Human Development. New York: John Wiley, vol. 1, pp. 942-98.

Rana, Meenal, Desiree B. Qin, and Carmina Vital-Gonzalez. 2019. Mistaken identities: The media and parental ethno-religious socialization in a Midwestern Sikh community. Religions 10: 571. [CrossRef]

Richert, Rebekah A., and Pehr Granqvist. 2013. Religious and spiritual development in childhood. In Handbook of the Psychology of Religion and Spirituality. Edited by Raymond Paloutzian and Crystal L. Park. New York: The Guilford Press, pp. 165-82. 
Roeser, Robert W., Sonia S. Issac, Mona Abo-Zena, Aerika Brittan, and Stephen J. Peck. 2008. Self and identity processes in spirituality and positive youth development. In Positive Youth Development and Spirituality: From Theory to Research. Edited by Richard M. Lerner, Robert W. Roeser and Erin Phelps. West Conshohocken: Templeton Foundation Press, pp. 74-105.

Schachter, Elli, and Avital B. Hur. 2019. The varieties of religious significance: An idiographic approach to study religion's role in adolescent development. Journal of Research on Adolescence 29: 291-307. [CrossRef]

Schwartz, Kelly Dean, William M. Bukowski, and Wayne T. Aoki. 2006. Mentors, friends, and gurus: Peer and nonparent influences on spiritual development. In The Handbook of Spiritual Development in Childhood and Adolescence. Edited by Eugene C. Roehlkepartain, Pamela E. King, Linda Wagener and Peter. L. Benson. Thousand Oaks: Sage, pp. 310-23.

Smith, Christian, and Melina L. Denton. 2005. Soul Searching: The Religious and Spiritual Lives of American Teenagers. New York: Oxford University Press.

Spencer, Margaret B. 2017. Privilege and critical race perspectives' intersectional contributions to a systems theory of human development. In New Perspectives on Human Development. Edited by Nancy Budwig, Elliot Turiel and Philip David Zelazo. New York: Cambridge University Press, pp. 287-312.

Spilka, Bernard. 2005. Religious practice, ritual, and prayer. In Handbook of Psychology of Religion and Spirituality. Edited by Raymond F. Paloutzian and Crystal L. Park. New York: The Guilford Press, pp. 365-77.

Vajpeyi, Ananya. 2016. The return of Sanskrit: How an old language caught up in India's new culture wars. World Policy Journal 33: 45-50. [CrossRef]

Williams, Raymond Brady. 2007. Religion and ethnicity in America. In Religious Reconstruction in the South Asian Diasporas. Edited by John R. Hinnells. New York: Palgrave Macmillan, pp. 143-57.

(C) 2020 by the authors. Licensee MDPI, Basel, Switzerland. This article is an open access article distributed under the terms and conditions of the Creative Commons Attribution (CC BY) license (http://creativecommons.org/licenses/by/4.0/). 